\title{
Superior performance of ablative glass coatings containing graphene nanosheets ${ }^{1}$
}

Eugenio Garcia, Andres Nistal2 ${ }^{2}$ M. Isabel Osendi, Pilar Miranzo ${ }^{3}$

Institute of Ceramics and Glass (ICV-CSIC), Madrid, Spain

\section{ABSTRACT}

Glass with compositions in the $\mathrm{Y}_{2} \mathrm{O}_{3}-\mathrm{Al}_{2} \mathrm{O}_{3}-\mathrm{SiO}_{2}$ (YAS) system are envisaged as promising high temperature protecting coatings for silicon carbide based composites intended for thermal protection systems (TPS) in aerospace applications. Recently, it has been shown that thermally sprayed YAS hybrid coatings containing a small amount of graphene nanoplateletes (GNPs) developed electrical functionality and higher mechanical compliance as compared to the blank YAS coating. Nevertheless, for TPS, it is crucial to know if they also have a good response under ablation conditions. Hence, the ablative behavior of YAS/GNPs coatings is here addressed using laboratory conditions of high temperature (up to $\left.1350^{\circ} \mathrm{C}\right)$ and blowing gasses. Results evidence that hybrid coatings, flame sprayed over $\mathrm{SiC}$ substrates, with just 1.05 vol.\% GNPs show enhanced ablation resistance withstanding up to 30 cycles at $1350^{\circ} \mathrm{C}$, without signs of spallation or substrate damage, which postulates them as promising TPS candidates. This

${ }^{1}$ This work was supported by the Spanish Ministry of Economy and Competitiveness (MINECO) and FEDER program under project IPT-2012-0800-420000 and by CSIC under project $201360 \mathrm{E} 063$.

${ }^{2}$ Presently at School of Mechanical and Aerospace Engineering, Queen's University, Belfast, UK.

3 pmiranzo@icv.csic.es 
favorable performance seems linked to their strongly direction dependent thermal conductivity, actually becoming in-plane enhanced and through-thickness reduced and thus constraining coating degradation just to the upper-most layer.

\section{KEYWORDS}

graphene, glass-ceramics, silicon carbide, coatings, thermal spraying, ablation, thermal conductivity, thermal protection systems

\section{Introduction}

Carbon and silicon carbide composites reinforced with carbon fibers $\left(\mathrm{C}_{\mathrm{f}} / \mathrm{C}\right.$ and $\mathrm{C}_{\mathrm{f}} / \mathrm{SiC}$, respectively) have been steadily substituting metals in a variety of applications due to their better thermomechanical performance. Particularly, the use of composites for high temperature heat shielding in aerospace applications has become essential ${ }^{1-5}$ in certain areas -as the nose, wings and fin leading edges of sub-orbital Reusable Launch Vehicles- where high reentry temperatures of 900 ${ }^{\circ} \mathrm{C}-1200{ }^{\circ} \mathrm{C}$ jointly with mechanical loads develop. ${ }^{1,2}$ Although $\mathrm{C}_{\mathrm{f}} / \mathrm{C}$ and $\mathrm{C}_{\mathrm{f}} / \mathrm{SiC}$ are the more promising materials for those zones, their rapid degradation in oxidizing atmospheres above $500^{\circ} \mathrm{C}$ makes mandatory their protection by means of ablative coatings..$^{6-9}$ The major concerns regarding coatings include reducing weight, decreasing vulnerability to orbital debris, while keeping minimal thermal conductivity and high-emissivity to ensure the maximum rejection of incoming convective heat through radiative heat transfer. ${ }^{4}$ In that context, we see hybrid 
graphene/glass-ceramic coatings as very promising materials, because of the exceptional properties of carbon allotropes as well as the heat resistance and the self-healing capabilities of glass-ceramics. ${ }^{10,11}$ The feasibility of the flame spraying method for coating $\mathrm{SiC}, \mathrm{C}_{\mathrm{f}} / \mathrm{SiC}$ and $\mathrm{C}_{\mathrm{f}} / \mathrm{C}$ substrates using glass $(\mathrm{G})$ and glassceramic (GC) compositions of the $\mathrm{Y}_{2} \mathrm{O}_{3}-\mathrm{Al}_{2} \mathrm{O}_{3}-\mathrm{SiO}_{2}$ (YAS) system has been proved previously by some of the present authors. ${ }^{12-14}$ These coatings were continuous, homogeneous, dense and presented good adhesion to $\mathrm{SiC}, \mathrm{C}_{\mathrm{t}} / \mathrm{SiC}$ and $\mathrm{C}_{\mathrm{f}} / \mathrm{C}$ substrates, particularly for SiC-based material. ${ }^{14}$ Furthermore, the inclusion of graphene nanoplatelets (GNPs) as filler for the YAS glass produced anisotropic hybrid coatings with aligned GNPs, exhibiting enhanced damage tolerance and also added electrical and thermal functionalities. ${ }^{11}$ Preliminary ablation tests performed in those YAS glass coatings showed endured ablation resistance at 900 ${ }^{\circ} \mathrm{C}$, but at higher temperatures the complete removal of the coating occurred. ${ }^{13}$ Although promising, these data were far from aimed for thermal protection systems (TPS). Hence, we pretend to increase the thermal resistance of these coating by choosing a YAS composition of higher melting temperature, able to crystallize into a glass-ceramic. Furthermore, the crucial effect that GNP fillers might have on the ablation behavior has not been addressed until now.

In the present work, we evaluate the performance of hybrid glass-ceramic/GNPs coatings, thermal sprayed over SiC substrates, under ablation tests at a maximum temperature of $1350{ }^{\circ} \mathrm{C}$ and also in thermal cycling, comparing with results of corresponding plain coating. The effect of ablation conditions on the coating 
microstructure and phases is assessed and, accordingly, an ablation mechanism is proposed for these GNP containing coatings.

\section{Experimental}

High purity (>99.7\%) $\mathrm{Y}_{2} \mathrm{O}_{3}$ (H.C. Starck,Germany), $\mathrm{Al}_{2} \mathrm{O}_{3}$ (SM8, Baikowski, France) and $\mathrm{SiO}_{2}$ (Alfa Aesar, Germany) powders were employed for the selected glassceramic (GC) composition $36.0 \mathrm{Y}_{2} \mathrm{O}_{3}: 18.0 \mathrm{Al}_{2} \mathrm{O}_{3}: 46.0 \mathrm{SiO}_{2}$ (in mol.\%). This composition was conditioned for obtaining spherical shaped particles of $\sim 30 \mu \mathrm{m}$ following the procedure described elsewhere.${ }^{15}$ Similar size granules for the GC composition with $10 \mathrm{vol}$ \% (6.5 wt \%) of graphene nanoplatelets (N008-100-P-10, Angstron Materials Inc., U.S.), labelled as GC/GNPs, were also prepared. ${ }^{11}$

SiC plates (Hexoloy S.A., Saint-Gobain) of $25 \times 25 \times 4 \mathrm{~mm}^{3}$ with a density of 3.15 $\mathrm{g} \cdot \mathrm{cm}^{3}$ were used as substrates, previously sand blasted and flame sprayed with a silicon bond coat for better coating anchoring..$^{16} \mathrm{GC}$ and GC/GNPs granules were thermally sprayed with an oxyacetylene gun (Casto-Dyn 8000; Eutectic Castolin, Spain), using acetylene and oxygen pressures of $7 \cdot 10^{4}$ and $4 \cdot 10^{5} \mathrm{~Pa}$, respectively, and gas flow rates of 23.7 and 32.5 in SLPM (standard litres per minute) for each gas; stand-off distance of $14 \mathrm{~cm}$ and a powder feed rate fixed at $10 \mathrm{~g} \cdot \mathrm{min}^{-1}$ were standard conditions for all coatings.

The naked-eye inspection revealed the colour difference between the plain GC (white) and the GC/GNPs coatings (black). The density of coatings was measured by the water immersion technique in freestanding coatings obtained by flame 
spraying the powders on metallic substrates. As certain vaporization of the nanoplatelets occurred during flame spraying, estimation of the remaining fraction in the coatings was done by thermogravimetric analyses, in a similar way as described in reference 11 . The glass transition temperature, the temperature for first crystallization and the melting point of the resulting glass-ceramic GC coating were recorded by differential thermal analysis (DTA-TGA, STA 409 NETZSCH) using a heating rate of $10 \mathrm{~K} \cdot \mathrm{min}^{-1}$.

The microstructure of the coatings was observed in fractured specimens, on the top surface and polished cross sections with a table-top Scanning Electron Microscope (SEM, TM1000, Hitachi, Japan). Changes in crystalline phases were followed by X-ray diffraction analyses (XRD, Xpert PRO, PANalytical, Netherlands) performed on the coatings top surface. For a precise observation of how ablation tests affected GNPs, Raman spectra were acquired from polished cross-sections of coatings (original and ablated) using a confocal $\mu$-Raman imaging system (Alpha 300 WITec GmbH, Germany) with a laser excitation wavelength of $532 \mathrm{~nm}$. Raman maps of $150 \times 150$ pixels (scanning area of $45 \mu \mathrm{m} \times 45 \mu \mathrm{m}$ ) and $30 \times 200$ pixels $(25 \mu \mathrm{m} \times 125 \mu \mathrm{m})$ were acquired, recording one spectrum per pixel and using 60 ms of acquisition time.

Two types of square specimens with different side lengths, $8.8 \mathrm{~mm}$ and $20 \mathrm{~mm}$, but same thickness $(0.86 \mathrm{~mm})$ were prepared for each coating/Si/SiC system. The approximated thickness of every layer were $\sim 0.20 \mathrm{~mm}$ for the coating, $\sim 0.06 \mathrm{~mm}$ for the Si bond coat and $\sim 0.6 \mathrm{~mm}$ for the $\mathrm{SiC}$ substrate. These specimens were used to measure the in-plane ( (ain-plane) - square of $20 \mathrm{~mm}$ side - and through- 
thickness ( $\alpha_{\text {thickness})}$ - $8.8 \mathrm{~mm}$ square - apparent thermal diffusivities at room temperature by the laser-flash method (Thermaflash 2200, Holometrix/Netzsch, U.S.). The thermal conductivity of the GC and GC/GNPs coatings (Kthickness) was calculated using analytical models for heat diffusion in layered systems ${ }^{17}$ and iterative software routines, using the athickness data of the corresponding systems and referred values for thermal properties of $\mathrm{SiC}$ and $\mathrm{Si}^{.16}$ The specific heat $\left(\mathrm{C}_{\mathrm{p}}\right)$ was estimated by the rule of mixtures using thermodynamic data. ${ }^{18}$

A special set-up was utilized for the apparent ain-plane of the systems, consisting of two masks, one to confine the laser pulse on the center of the specimen surface, into a circle of $r_{0}=2.5 \mathrm{~mm}$ radius, and another to define an annulus of radius $r=$ 2.2ro on the opposite surface facing the IR detector. The recorded temperature rise due to the radial heat flow is fitted by a two-dimensional model. ${ }^{19}$ Diffusivity data were averaged over at least 5 measurements.

Ablative and cycling tests were performed by focusing the oxyacetylene flame on the coating surface at a stand-off distance of $9 \mathrm{~cm}$, using the same conditions above described but adjusting the gas flow (see details in Table I) to achieve the target temperatures, namely 900 and $1200^{\circ} \mathrm{C}$ for ablation and $1350{ }^{\circ} \mathrm{C}$ for thermal cycling. The surface temperature of the exposed specimen (coating face) was continuously recorded during ablation tests by an IR pyrometer (IMPAC IGAR 12LO, LumaSense Tech., US) focussed on the coating surface. The temperature of the back side of the SiC substrate was logged by a thermocouple attached to it and protected from the flame. The thermal exposure was cut-off after 30 s of holding at the set point temperature. The cycling tests were done by focusing successively 
the flame over the coating -until the temperature of $1350{ }^{\circ} \mathrm{C}$ was reached- and then blowing air onto the specimen -at 3 bars of pressure- to rapidly cool down the surface, typically at $200{ }^{\circ} \mathrm{C}$ in $\sim 30 \mathrm{~s}$. Each heating-cooling cycle was repeated 30 times in two different samples.

\section{Results and discussion}

The cross sections of the GC and GC/GNPs sprayed coatings are shown in Fig. 1, where perfect attachment between the different layers is perceived. Both coatings are dense, continuous and have a thickness of $\sim 130 \mu \mathrm{m}$. Plain CG coating is formed by splats (see insert in Fig. 1a) of different grey contrast, produced by local variations of composition, and contains some disperse pores. On the other hand, the elongated features observed at the splat boundaries in the GC/GNPs coating (Fig. 1b) correspond to the nanoplatelets. ${ }^{11}$ As the DTA of the GC ground coating (Fig. 2a) shows, temperatures of glass transition ( $\left.T_{g}\right)$, first crystallization $\left(T_{c}\right)$ and melting $\left(T_{m}\right)$ are 929,1055 and $1525{ }^{\circ} \mathrm{C}$, respectively. Therefore, present GC coating melts at a temperature $\sim 100{ }^{\circ} \mathrm{C}$ above that registered for the previously formulated coating, $G$ glass $^{13}\left(T_{m}=1418 \quad \stackrel{\circ}{ } \mathrm{C}\right)$ of composition 19.2 $\mathrm{Y}_{2} \mathrm{O}_{3}: 32.4 \mathrm{Al}_{2} \mathrm{O}_{3}: 48.4 \mathrm{SiO}_{2}$ (in mol\%); besides, $\mathrm{GC}$ coating shows a narrower viscous flow window $\left(\sim 126 \stackrel{\circ}{\circ}\right.$ ) than that shown by $\mathrm{G}$ coating $\left(200^{\circ} \mathrm{C}\right)$ of higher $\mathrm{Al}_{2} \mathrm{O}_{3}: \mathrm{Y}_{2} \mathrm{O}_{3}$ ratio (1.7 versus 0.5 of $\mathrm{GC}$ ). ${ }^{20}$ Therefore, the present $\mathrm{GC}$ coating is expected to show improved thermal resistance and satisfactory self-healing ability.

The remaining GNPs in the GC hybrid coating, as determined by TGA, amount to 1.05 vol. $\%$, representing $16 \%$ of the initial content. Surprisingly, this percentage is 
noticeably lower than that previously obtained for the $G$ hybrid coating with 3.54 vol $\%$ of lasting GNPs. ${ }^{11}$ The lower amount of surviving GNPs for the GC coating may be explained by both its higher melting temperature and the lower amount of energy absorbed by the GC feedstock granules during spraying for reacting and melting, compared to the $\mathrm{G}$ feedstock; as seen in Fig. 2b. Hence, the total energy consumption estimated by integrating the area of DTA bands for the $G$ and GC feedstock, from the first reaction event up to the melting (1430 and $1525^{\circ} \mathrm{C}$, respectively), gave $11 \mu \mathrm{V} \cdot \mathrm{s} \cdot \mathrm{mg}^{-1}$ for $\mathrm{G}$ and $2 \mu \mathrm{V} \cdot \mathrm{s} \cdot \mathrm{mg}^{-1}$ for $\mathrm{GC}$. In this way, during spraying, there would be a higher amount of heat available in the flame for GNPs damaging, up to higher temperatures and for longer times, in the case of GC granules. This finding appears decisive when designing new glass-ceramic/GNPs compositions for thermal spraying processing.

The ablation test set-points of $900{ }^{\circ} \mathrm{C}$ and $1200{ }^{\circ} \mathrm{C}$ are reached on both coatings after 50 and $20 \mathrm{~s}$, respectively; the faster rate for the $1200{ }^{\circ} \mathrm{C}$ test owing to the higher power flame used (Table I). During the $30 \mathrm{~s}$ of thermal exposure, the surface coating temperature monotonically rose until the top values of $949^{\circ} \mathrm{C}$ $(\mathrm{GC} / \mathrm{GNP})$ and $962^{\circ} \mathrm{C}(\mathrm{GC})$ for the $900^{\circ} \mathrm{C}$ treatment, whereas $1352^{\circ} \mathrm{C}(\mathrm{GC} / \mathrm{GNP})$ and $1459^{\circ} \mathrm{C}(\mathrm{GC})$ were registered for the $1200{ }^{\circ} \mathrm{C}$ ablation test (as an example, heating curves of the $120{ }^{\circ} \mathrm{C}$ test are depicted in Fig. 3a). Hence, temperatures in the hybrid coating are comparatively lower than in the corresponding plain coating for both set conditions, and the same is observed for the back side temperatures of the SiC substrates, which could be explained by the higher emissivity -as the hybrid coatings are black- and anisotropic thermal conductivity of the GNP 
containing coatings. As seen in Table II, ain-plane of the GC/GNPs system increases by $\sim 8 \%$ (from 3.43 to $3.71 \times 10^{-5} \mathrm{~m}^{2} \cdot \mathrm{s}^{-1}$ ) despite the existence in the coating of just $\sim 1$ vol. $\%$ GNPs, whereas the $a_{\text {thickness }}$ is reduced by $38 \%$ (from 0.93 to $0.58 \times 10^{-5}$ $\left.\mathrm{m}^{2} \cdot \mathrm{s}^{-1}\right)$. Furthermore, the Kthickness calculated for the GC/GNPs coating $\left(0.31 \mathrm{~W} \cdot \mathrm{m}^{-}\right.$ $\left.{ }^{1} \cdot \mathrm{K}^{-1}\right)$ is $27 \%$ lower than the value obtained for the GC coating $\left(0.43 \mathrm{~W} \cdot \mathrm{m}^{-1} \cdot \mathrm{K}^{-1}\right)$. This anisotropic behavior is similar to that observed in bulk ceramic materials having oriented GNPs lying in a perpendicular direction to the heat flux, ${ }^{21}$ being the reduction for the cross-plane thermal conductivity mainly related to the intrinsically lower conductivity of the graphite in the c direction. However, it differs from the thermal performance previously reported for the G glass coating containing 3.6 vol.\% GNPs; in that case, an augment of $\mathrm{k}$ by $30 \%$ was measured for both orientations because GNPs were also connected in the direction perpendicular to the coating surface. ${ }^{11}$ For the present coatings, the reduced amount of GNPs intensifies the thermal anisotropy of the hybrid GC/GNP coating (the $\alpha_{\text {in- }}$ plane/ $\alpha_{\text {thickness }}$ ratio rises from 3.7 to 6.4 ), which foresees good performance for thermal shield purposes, as they would enhance the in-plane release of heat avoiding hot spots while hindering heat propagation towards the substrate in the through-thickness direction. Furthermore, the higher emissivity of GC/GNPs compare to GC favours rejection of incoming convective heat through radiative heat transfer.

The formation of blisters was noticed on the GC coating surface, probably caused by the simultaneous action of the blowing gases and the reduction of glass viscosity due to the increasing temperatures, in a similar way to which $G$ 
composition tested at $900{ }^{\circ} \mathrm{C}$ behaved. ${ }^{13}$ However, the GC coating develops significantly smaller size bubbles because of its comparatively higher $\mathrm{Tg}$ and narrower viscous flow window (Fig. 2). Besides, the GC coating survived the 1200 ${ }^{\circ} \mathrm{C}$ ablation test without spalling. Therefore, the new GC coating has better thermal resistance than the $\mathrm{G}$ one, which was entirely removed above $900{ }^{\circ} \mathrm{C} .{ }^{13}$ On the other hand, bubbles are hardly detected in the GC/GNPs coating tested at $900{ }^{\circ} \mathrm{C}$ and $1200{ }^{\circ} \mathrm{C}$ as it would have higher viscosity associated to both the lower temperature reached during the tests (Fig. 3b) and the presence of GNPs. These coatings turned their original black colour into white, suggesting the GNPs burning close to the surface.

The improved resistance to ablation caused by the GNPs is quite evident from the coatings cross section images of Fig. 4. The GC/GNPs coating tested at $900{ }^{\circ} \mathrm{C}$ (Fig. 4c) seems hardly affected whereas the plain GC coating (Fig. 4a) shows some thickness reduction $(26 \mu \mathrm{m})$ and bubbles formation on the surface. At $1200^{\circ} \mathrm{C}$, the plain GC coating (Fig. 4b) reveals extended cavitation next to the $\mathrm{Si}$ bond coat, generated by the expansion of dissolved gases that cannot escape. This harsh damage is not observed in the GC/GNPs coating (Fig. 4d), according to the lower temperatures achieved and the reported gas barrier properties of graphene; ${ }^{22}$ hence, GNPs may limit the penetration of combustion gasses considering that they form an almost continuous layer.

The distribution of GNPs across the GC/GNPs hybrid coatings before and after ablation tests was evaluated on the coating cross-section by Raman spectroscopy (Fig 5). The mapping built by filtering the IG Raman band characteristic of the 
graphitic structures $^{23}$ on an area of $25 \mu \mathrm{m} \times 125 \mu \mathrm{m}$ reveals a network of GNPs along the entire as-sprayed coating (Fig. 5a), whereas after ablation at $1200{ }^{\circ} \mathrm{C}$ (Fig. 5b), GNPs dissapear in a degraded top layer of $\sim 45 \mu \mathrm{m}$, remaining unaltered in the inner area of the coating cross section. The $\mathrm{ID}_{\mathrm{D}} / \mathrm{IG}_{\mathrm{G}}$ ratio calculated for the window averaged spectra recorded in the central area of the coatings were very similar (0.40-0.43) for the as-sprayed and ablated coating (Fig. $5 c, d)$, thus proving the low degradation of the inner GNPs during ablation despite reaching surface temperatures of $1390{ }^{\circ} \mathrm{C}$. These $\mathrm{ID}_{\mathrm{D}} / \mathrm{IG}_{\mathrm{G}}$ values were always higher than that of the original GNPs ${ }^{11}$ probably because of the higher contribution of the defective GNP edges when analyzing the coating cross-section. The confinement of GNPs degradation at the uppermost surface proves that the interaction with the hot gasses is restrained to a certain depth, slowing the degradation underneath, and consequently providing the hybrid coating with a higher thermal load resistance under ablation conditions. The thickness of the degraded layer for each coating as function of the maximum temperature reached during the ablation test is shown in Fig. 3b. This thickness is significantly lower in the case of the GC/GNPs coating for both ablation temperatures which confirms again the GNPs positive effect.

As seen in Fig. 6, the XRD patterns of the as-sprayed coatings display the characteristic amorphous bump, with a superimposed diffraction peak at $26^{\circ}$ associated to the (003) graphite reflection in the case of the hybrid coating. Therefore, they were essentially amorphous, which must be connected to the fast cooling rates of the molten droplets after impinging on the substrate $\left(\sim 10^{8}-10^{9}\right.$ $\left.\mathrm{K} \cdot \mathrm{s}^{-1}\right)^{24}$ as the $\mathrm{GC}$ composition is outside of the glass forming region of the $\mathrm{Y}_{2} \mathrm{O}_{3}$ - 
$\mathrm{Al}_{2} \mathrm{O}_{3}-\mathrm{SiO}_{2}$ phase equilibrium diagram. ${ }^{25-27}$ After ablation at $900{ }^{\circ} \mathrm{C}$, an extensive crystallization is not observed, particularly for the GC/GNPs coating that still exhibits a marked amorphous halo, inferring that GNPs hindered crystallization probably because of the lower achieved temperature. Crystallization augmented in both coatings after ablation at $1200{ }^{\circ} \mathrm{C}$, as reached temperatures were well above the first crystallization temperature of the GC composition (1055 ${ }^{\circ} \mathrm{C}$, see Fig. $2 \mathrm{a}$ ), showing diffraction peaks of yttrium silicates (YAG and O-apatite $\mathrm{Y}_{4.67}\left(\mathrm{SiO}_{4}\right)_{3} \mathrm{O}$ ) and aluminum yttrium oxide phases $\left(\mathrm{Al}_{2} \mathrm{Y}_{4} \mathrm{O}_{9}\right)$, which do not correspond to those predicted by the corresponding equilibrium phase diagram ${ }^{28}$ (YAG, $\mathrm{Y}_{2} \mathrm{SiO}_{5}$ and $\mathrm{Y}_{2} \mathrm{Si}_{2} \mathrm{O}_{7}$ ). This crystallization has been also proved by Raman point spectra recorded on individual splats ("O" in Fig. 4a,b) that showed just the band at 950 $\mathrm{cm}^{-1}$ ascribed to aluminosilicate glasses ${ }^{29}$ in the as-sprayed GC/GNPs coating but some additional bands associated to crystalline phases for the same coating ablated at $1200{ }^{\circ} \mathrm{C}$; this fact reveals that temperatures above the $\mathrm{Tg}$ of $\mathrm{GC}$ (1055 ${ }^{\circ}$ C) were achieved inside coating during ablation.

The high temperature stability and performance of the GC/GNPs coating was further proved by thermal cycling tests (Table I), where no-spallation signs were detected after 30 cycles at $1350 \stackrel{\circ}{\circ}$. Observation of the coating cross section (Fig. 7a) shows voids formation across the coating although it still remains perfectly attached to the $\mathrm{Si}$ bond coat, without any indication of damage along the coating/bond-coat and bond-coat/substrate interfaces. The XRD pattern of the top surface after cycling (Fig. 7b) showed crystallization of yttrium mono- and disilicates together with $Y A G$ as the main phases, in agreement with the $\mathrm{Y}_{2} \mathrm{O}_{3}-\mathrm{Al}_{2} \mathrm{O}_{3}$ - 
$\mathrm{SiO}_{2}$ phase equilibrium diagram predictions. ${ }^{28}$ Therefore, the hybrid GC/GNPs coating successfully accomplished the goal of harsh thermal protection at $1350^{\circ} \mathrm{C}$. Moreover, this type of ablative coatings could be re-sprayed, after removal of the damaged coating, then allowing convenient in-situ restoring.

\section{Conclusions}

Thick glass-ceramic/multilayer graphene hybrid coatings flame sprayed on $\mathrm{SiC}$ substrates from granules of $\mathrm{Y}_{2} \mathrm{O}_{3}-\mathrm{Al}_{2} \mathrm{O}_{3}-\mathrm{SiO}_{2}$ powders and graphene nanoplatelets are visualized as promising candidates for TPS. With just 1 vol.\% of GNPs, the hybrid coating shows enhanced ablation resistance as compared to the blank coating, in fact protecting the substrate from harsh exposures at $1350{ }^{\circ} \mathrm{C}$ for at least $30 \mathrm{~s}$. They also resist up to 30 cycles at a $1350{ }^{\circ} \mathrm{C}$ without spallation or substrate damage. This enhanced ablation resistance is linked to the higher emissivity and improved anisotropy in thermal conductivity of the hybrid coating which limits hot spots generation while hinder heat propagation towards the substrate. The ablation confines GNPs degradation just at the uppermost layer because the horizontally arranged GNP network limits the interaction of the hot gasses with the underneath coating, consequently providing the hybrid coating with a higher thermal load resistance.

\section{References}

1. D. E. Glass, "Ceramic matrix composite (CMC) thermal protection systems (TPS) and hot structures for hypersonic vehicles"; pp. 1-36 in 15th AIAA 
space planes and hypersonic systems and technologies conference.

Dayton, Ohio, 2008.

2. B. Behrens and M. Muller, "Technologies for Thermal Protection Systems Applied on Re-usable Launcher", Acta Astronaut., 55 [3] 529-536 (2004).

3. P. Sanoj and B. Kandasubramanian, "Hybrid Carbon-Carbon Ablative Composites for Thermal Protection in Aerospace" J. Compos., 2014825607 15pp. (2014)

4. J. Young and R. Crippen, "Thermal Protection Systems"; pp 182-199 in Vol. 3409, Wings in Orbit: Scientific and Engineering Legacies of the Space Shuttle, 1971- 2010. Edited by W. Hale et al. Government Printing Office, Washington DC, 2011.

5. W. Krenkel and F. Berndt, "C/C-SiC Composites for Space Applications and Advanced Friction Systems," Mater. Sci. Eng. A, 412 [1] 177-181 (2005).

6. J.E. Sheehan, K.W. Buesking and B.J. Sullivan, "Carbon-Carbon Composites," Annu. Rev. Mater. Sci., 24 [1] 19-44 (1994).

7. I. Spitsberg and J. Steibel, "Thermal and Environmental Barrier Coatings for $\mathrm{SiC} / \mathrm{SiC} \mathrm{CMCs}$ in Aircraft Engine Applications," Int. J. Appl. Ceram. Technol., 1 [4] 291-301 (2004).

8. L. He-Jun, X. Hui, F. Qian-Gang, Z. Yu-Lei, S. Xiao-Hong, and L. Ke-Zhi, "Research Status and Prospect of Anti-Oxidation Coatings for Carbon/Carbon Composites," J. Inorg. Mater., 25 [4] 337-343 (2010). 
9. I. Sakraker and C.O. Asma, "Experimental Investigation of Passive/Active Oxidation Behavior of SiC Based Ceramic Thermal Protection Materials Exposed to High Enthalpy Plasma," J. Eur. Ceram. Soc., 33 [2] 351-359 (2013).

10.F. Smeacetto, M. Ferraris and M. Salvo, "Multilayer Coating with Selfsealing Properties for Carbon-Carbon Composites," Carbon, 41 [11] 2105-2111 (2003).

11.E. Garcia, A. Nistal, A. Khalifa, Y. Essa, F. Martín de la Escalera, M. I. Osendi and P. Miranzo, "Highly Electrically Conducting Glass-Graphene Nanoplatelets Hybrid Coatings," ACS Appl. Mater. Interfaces, 7 [32] 17656-17662 (2015).

12. M.A. Sainz, M.I. Osendi and P. Miranzo, "Protective Si-Al-O-Y Glass Coatings on Stainless Steel in Situ Prepared by Combustion Flame Spraying," Surf. Coat. Technol., 202 [9]1712-1717 (2008).

13. E. García, A. Nistal; F. Martín de la Escalera, A. Khalifa, M.A. Sainz, M.I. Osendi and P. Miranzo, "Thermally Sprayed $\mathrm{Y}_{2} \mathrm{O}_{3}-\mathrm{Al}_{2} \mathrm{O}_{3}-\mathrm{SiO}_{2}$ Coatings for High Temperature Protection of SiC Ceramics," J. Therm. Spray Technol., 24 [1-2] 185-193 (2015).

14. C. Marraco-Borderas, A. Nistal, E. García, M. A. Sainz, F. Martín de la Escalera, Y. Essa and P. Miranzo, "Adhesion of $\mathrm{Y}_{2} \mathrm{O}_{3}-\mathrm{Al}_{2} \mathrm{O}_{3}-\mathrm{SiO}_{2}$ coatings to typical aerospace substrates," (Spanish). Bol. Soc. Ceram. V. In-press (2016). 
15. E. García, J. Mesquita-Guimarães, P. Miranzo and M.I. Osendi, "Porous Mullite and Mullite- $\mathrm{ZrO}_{2}$ Granules for Thermal Spraying Applications," Surf. Coat. Technol., 205 [17] 4304-4311 (2011).

16. A. Nistal, E. García, C. García-Diego, M.I. Osendi and P. Miranzo, "Flame Spraying of Adherent Si Coatings on SiC Substrates," Surf. Coat. Technol., 270 8-15 (2015).

17. T. Y. R. Lee, "Thermal Diffusivity of Dispersed and Layered Composites"; Ph.D. Thesis, Purdue University, West Lafeyette, IN, 1977.

18. A. Roine, "Outokumpu HSC Chemistry for Windows, version 5.11"; Outokumpu Research: Pori, Finland, 2002.

19. A. B. Donaldson and R.E. Taylor, "Thermal Diffusivity Measurement by a Radial Heat Flow Method," J. Appl. Phys., 46 [10] 4584-4589 (1975).

20. L. Wu, G. Liu, J. Li, B. He, Z. Yang and Y. Chen, "Dependence of GlassForming Ability on Starting Compositions in $\mathrm{Y}_{2} \mathrm{O}_{3}-\mathrm{Al}_{2} \mathrm{O}_{3}-\mathrm{SiO}_{2}$ System," Ceram-Silikaty, 55 [3] 228-231 (2011).

21.P. Miranzo, E. García, C. Ramírez, J. González-Julián, M. Belmonte and M.I. Osendi, "Anisotropic Thermal Conductivity of Silicon Nitride Ceramics Containing Carbon Nanostructures," J. Eur. Ceram. Soc., 32 [8] 1847-1854 (2012)

22. J.S. Bunch, S.S. Verbridge, J. S. Alden, A. M. van der Zande, J.M. Parpia, H. G. Craighead and P.L. McEuen, "Impermeable Atomic Membranes from Graphene Sheets," Nano Lett., 8 [8] 2458-2462 (2008). 
23. A. C. Ferrari, J.C Meyer, V. Scardaci, C. Casiraghi, M. Lazzeri, M. F. Mauri, S. Piscanec, D. Jiang, K.S. Novoselov, S. Roth and A.K. Geim, "Raman Spectrum of Graphene and Graphene Layers," Phys. Rev. Lett., 97 [18] 187401-187404 (2006).

24. L. Bianchi, A.C. Leger, M. Vardelle, A. Vardelle, and P. Fauchais, "Splat Formation and Cooling of Plasma-Sprayed Zirconia," Thin Solid Films, 305 [1] 35-47 (1997).

25. M.J. Hyatt and D.E. Day, "Glass Properties in the Yttria-Alumina-Silica System," J. Am. Ceram. Soc., 70 [10] C283-C287 (1987).

26. J.E. Shelby, S.M. Minton, C.E. Lord and M.R. Tuzzolo, "Formation and Properties of Yttrium Aluminosilicate Glasses," Phys. Chem. Glasses, 33 [3] 93-98 (1992).

27. K. Morita, A. Umezawa, S. Yamato, and A. Makishima, "Surface-Roughness of Yttria-Containing Aluminosilicate Glass-Ceramics as Indicative of Their Machinability," J. Am. Ceram. Soc., 76 [7] 1861-1864 (1993).

28. U. Kolitsch, H.J. Seifert, T. Ludwig, and F. Aldinger, "Phase Equilbria and Crystal Chemistry in the $\mathrm{Y}_{2} \mathrm{O}_{3}-\mathrm{Al}_{2} \mathrm{O}_{3}-\mathrm{SiO}_{2}$ System," J. Mater. Res., 14 [2] 447-455 (1999).

29. J. T. Kohli,R.A. Condrate, J.R. Shelby, "Raman and Infrared Spectra of Rare Earth Aluminosilicate Glasses," Phys. Chem. Glasses, 34 [3] 81-87 (1993). 


\section{Captions}

Figure 1. SEM images of the polished cross-sections of (a) GC and (b) GC/GNPs coatings. The inserts show higher magnification details of the coatings.

Figure 2. DTA curves of the plain GC and G compositions for (a) the coatings indicating the temperatures for glass transition $\left(T_{g}\right)$, first crystallization event $\left(T_{c}\right)$ and melting $\left(T_{m}\right)$; and $(b)$ the original feedstock powders where grey areas show the exothermic and endothermic events integrated for the calculation of the energy consumed for the reacting and melting processes during spraying.

Figure 3. (a) Temperatures measured at the front surface of the GC and GC/GNPs coatings and the back surface of the $\mathrm{SiC}$ substrate versus ablation time during the tests at $1200{ }^{\circ} \mathrm{C}$. (b) Thickness of the degraded top layer vs. the maximum temperature reached during ablation tests at 900 and $1200 \stackrel{\circ}{ } \mathrm{C}$.

Figure 4. SEM micrographs of the cross sections of the GC and GC/GNPs coatings after $900(\mathrm{a}, \mathrm{c})$ and $1200^{\circ} \mathrm{C}(\mathrm{b}, \mathrm{d})$ ablation tests.

Figure 5. Raman studies done on the GC/GNPs hybrid coating: (a) as-sprayed and (b) after the ablation test at $1200{ }^{\circ} \mathrm{C}$, including optical images of the analysed region and Raman maps of the intensity of the G-band of GNPs acquired on the red boxed region. Representative Raman spectra of as-sprayed (c) and (d) ablated coating corresponding to point analyses of GNPs (X) and GC splats (O) and an average spectrum recorded in an area of $45 \mu \mathrm{m} \times 45 \mu \mathrm{m}$ of the central part of the coatings. 
Figure 6. XRD patterns of the surface of the GC and GC/GNPs coatings (assprayed and ablated at 900 and $1200{ }^{\circ} \mathrm{C}$ ), showing evolution of crystalline phases with the ablation temperature.

Figure 7. SEM micrograph of the GC/GNPs coating cross-section (a) and XRD pattern of the top surface (b) after 30 cycles at $1350 \stackrel{\circ}{\circ}$. 
Table I. Flow of gases employed in the different high temperature tests.

\begin{tabular}{cccc}
\hline & $\begin{array}{c}\text { Ablation at } \\
900{ }^{\circ} \mathrm{C}\end{array}$ & $\begin{array}{c}\text { Ablation at } \\
1200{ }^{\circ} \mathrm{C}\end{array}$ & $\begin{array}{c}\text { Cycling at } \\
1350{ }^{\circ} \mathrm{C}\end{array}$ \\
\hline $\mathrm{O}_{2}(\mathrm{SLPM})$ & 16.3 & 18.8 & 21.5 \\
$\mathrm{C}_{2} \mathrm{H}_{2}$ (SLPM) & 12.0 & 13.8 & 13.8 \\
\hline Standard Litres per Minute & & & \\
\hline
\end{tabular}

*SLPM: Standard Litres per Minute 
Table II. Values of apparent in-plane ( $\left.\alpha_{\text {in-plane }}\right)$ and through-thickness ( $\alpha_{\text {thickness }}$ ) thermal diffusivity measured for the coating/Si/SiC systems. Through-thickness thermal conductivity (Kthickness) values calculated for the coatings using multilayer models are also shown.

\begin{tabular}{lcc|c}
\hline \multicolumn{3}{c}{$\begin{array}{l}\alpha_{\text {in }} \text { plane }\left(\mathrm{m}^{2} \cdot \mathrm{s}^{-1}\right)\left(\mathrm{x} 10^{-5}\right) \\
\text { coating/Si/SiC }\end{array}$} & $\begin{array}{c}\alpha_{\text {thickness }}\left(\mathrm{m}^{2} \cdot \mathrm{s}^{-1}\right)\left(\mathrm{x} 10^{-5}\right) \\
\text { Kthickness }\left(\mathrm{W} \cdot \mathrm{m}^{-1} \cdot \mathrm{K}^{-1}\right) \\
\text { coating }\end{array}$ \\
\hline GC & 3.43 & 0.93 & 0.43 \\
GC/GNPs & 3.71 & 0.58 & 0.31 \\
\hline
\end{tabular}

Statistical deviations were $10 \%, 5 \%$ and $7 \%$ for $\alpha_{\text {in-plane, }} \alpha_{\text {thickness }}$ and $K_{\text {thickness, }}$ respectively. 
Figures paper Superior performance of ablative glass coatings containing graphene nanosheets
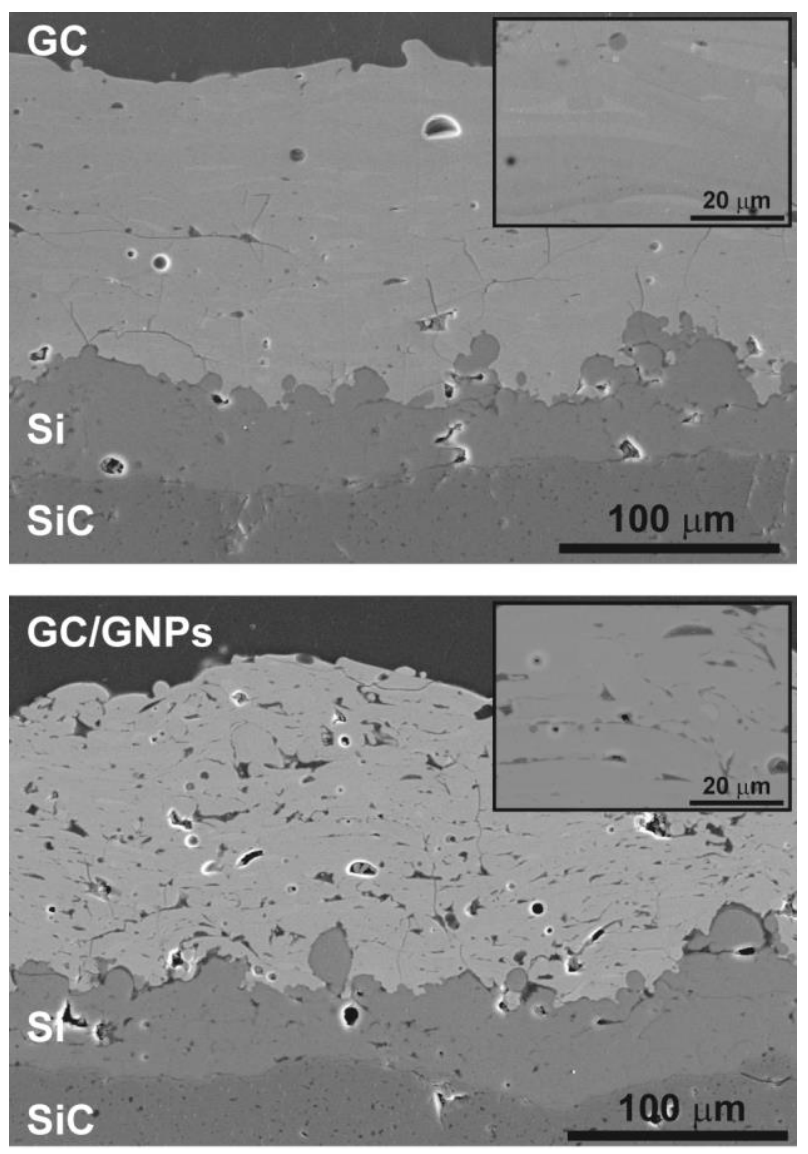

Figure 1. SEM images of the polished cross-sections of (a) GC and (b) GC/GNPs coatings. The inserts show higher magnification details of the coatings. 

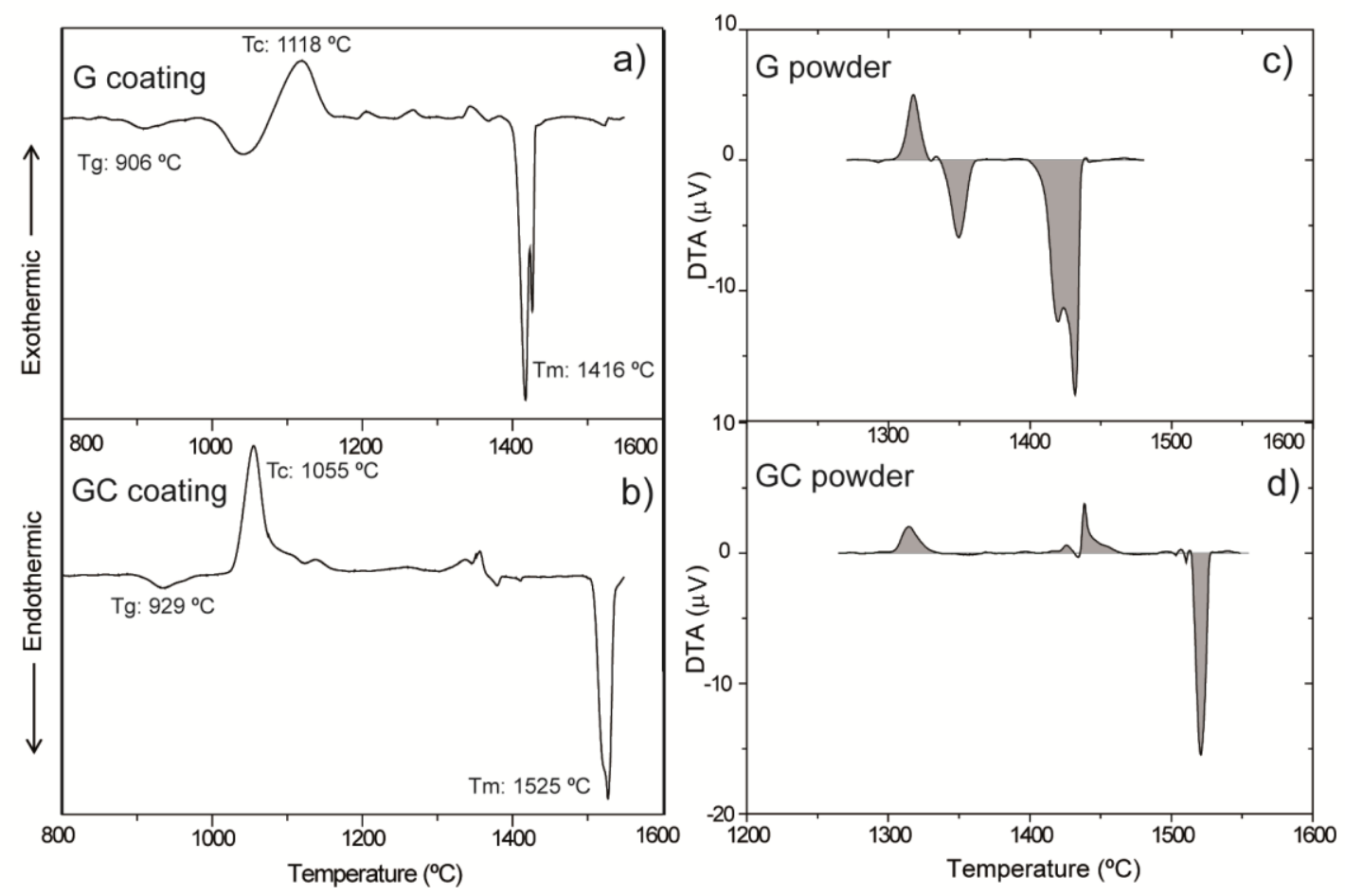

Figure 2. DTA curves of the plain GC and G compositions for (a) the coatings indicating the temperatures for glass transition $\left(T_{g}\right)$, first crystallization event $\left(T_{c}\right)$ and melting $\left(T_{m}\right)$; and (b) the original feedstock powders where grey areas show the exothermic and endothermic events integrated for the calculation of the energy consumed for the reacting and melting processes during spraying. 

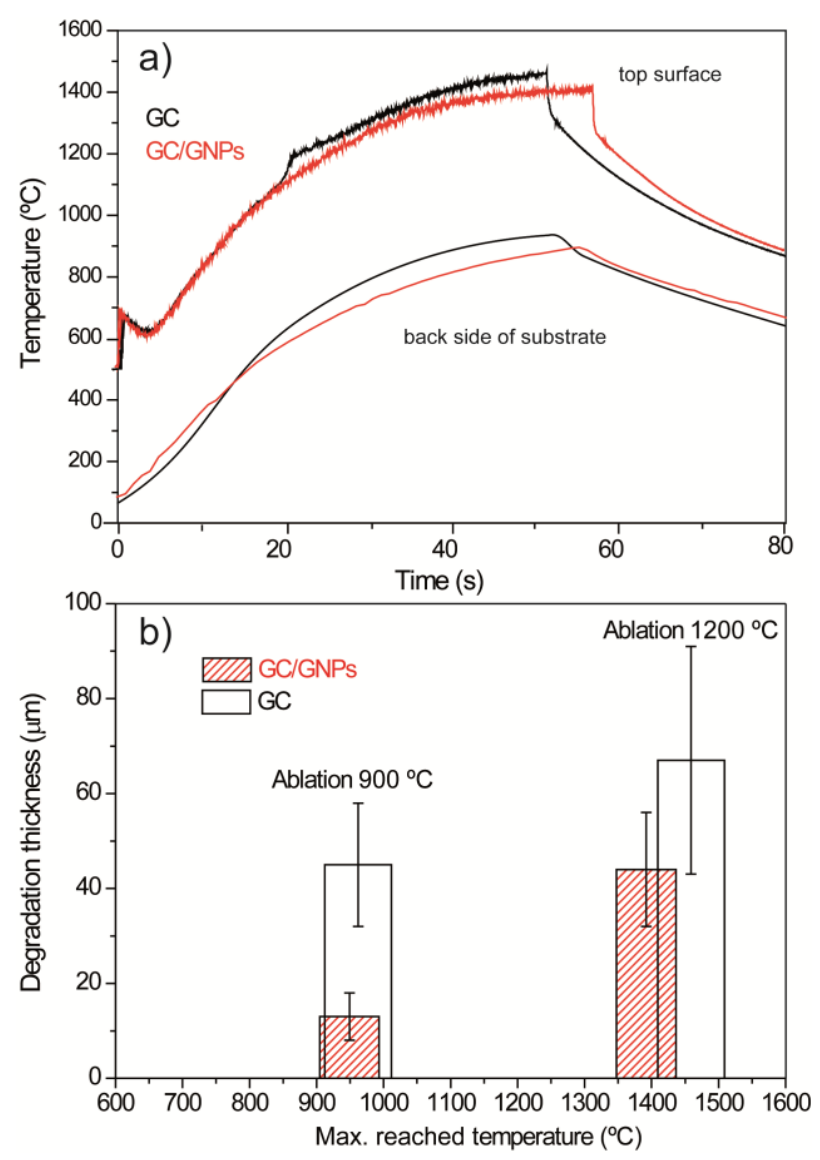

Figure 3. (a) Temperatures measured at the front surface of the GC and GC/GNPs coatings and the back surface of the $\mathrm{SiC}$ substrate versus ablation time during the tests at $1200 \stackrel{\circ}{ } \mathrm{C}$. (b) Thickness of the degraded top layer vs. the maximum temperature

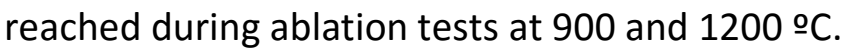



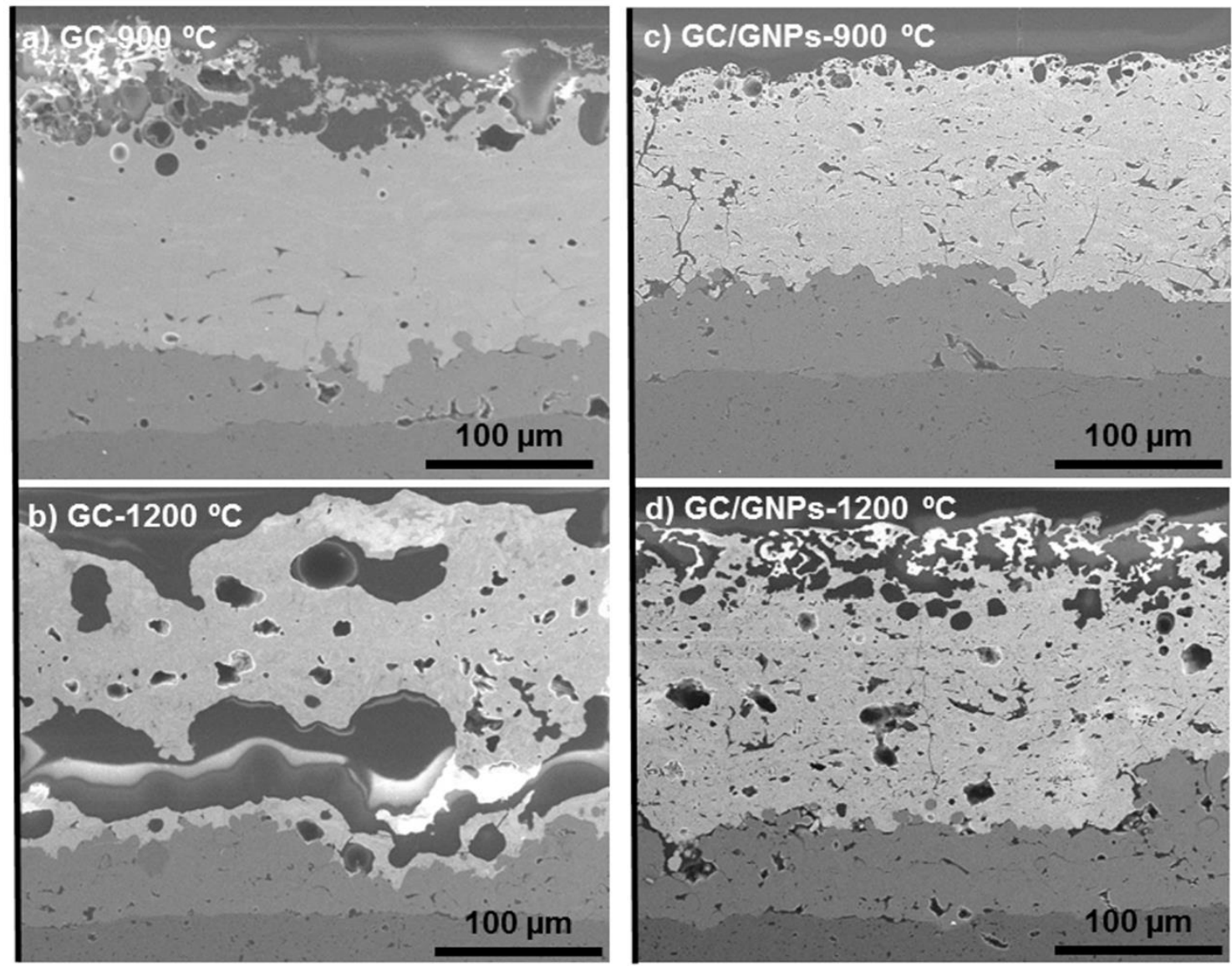

Figure 4. SEM micrographs of the cross sections of the GC and GC/GNPs coatings after $900(a, c)$ and $1200 \cong \mathrm{C}(\mathrm{b}, \mathrm{d})$ ablation tests. 

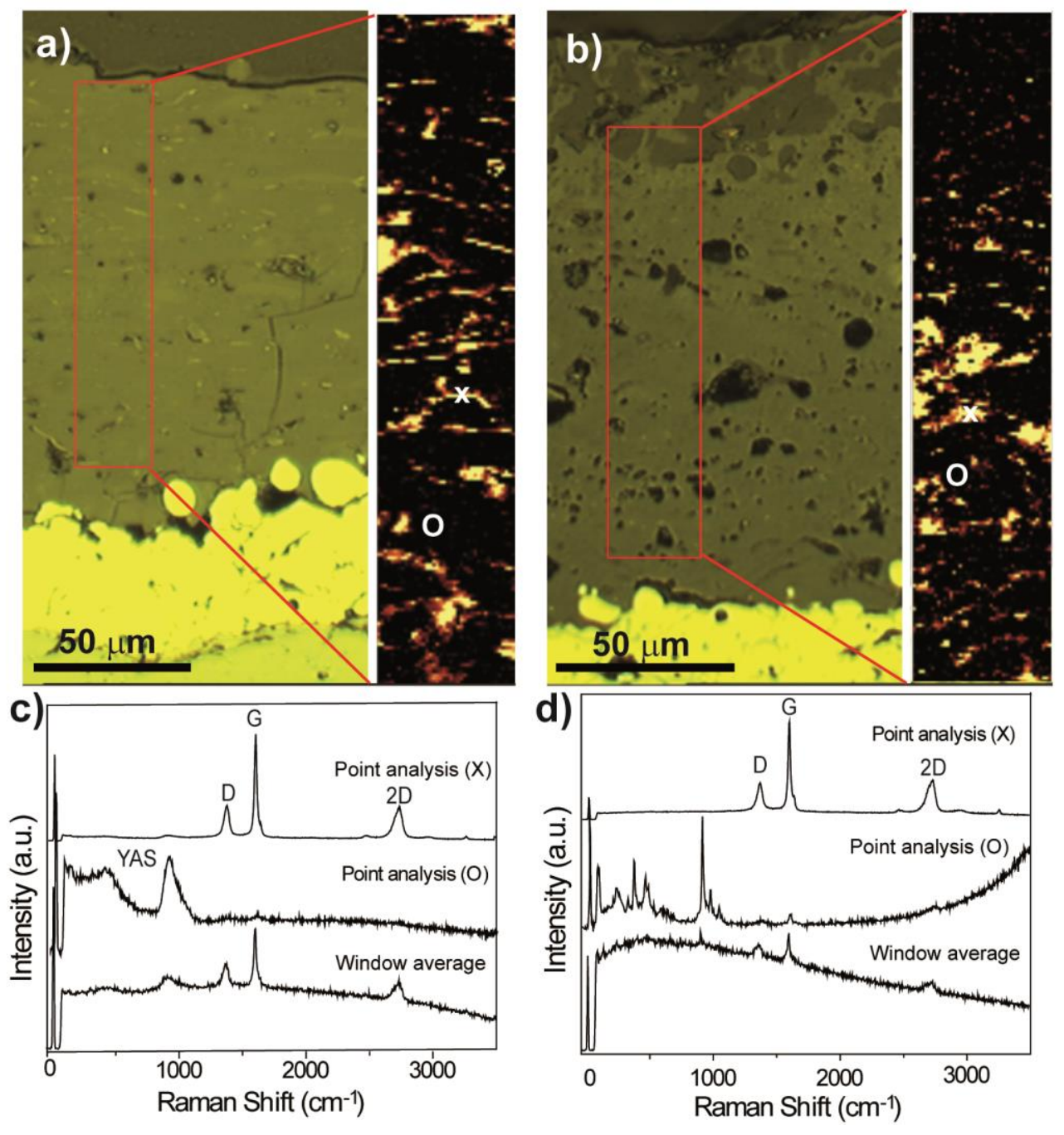

Figure 5. Raman studies done on the GC/GNPs hybrid coating: (a) as-sprayed and (b) after the ablation test at 1200 으, including optical images of the analysed region and Raman maps of the intensity of the G-band of GNPs acquired on the red boxed region. Representative Raman spectra of as-sprayed (c) and (d) ablated coating corresponding to point analyses of GNPs $(X)$ and GC splats $(O)$ and an average spectrum recorded in an area of $45 \mu \mathrm{m} \times 45 \mu \mathrm{m}$ of the central part of the coatings. 


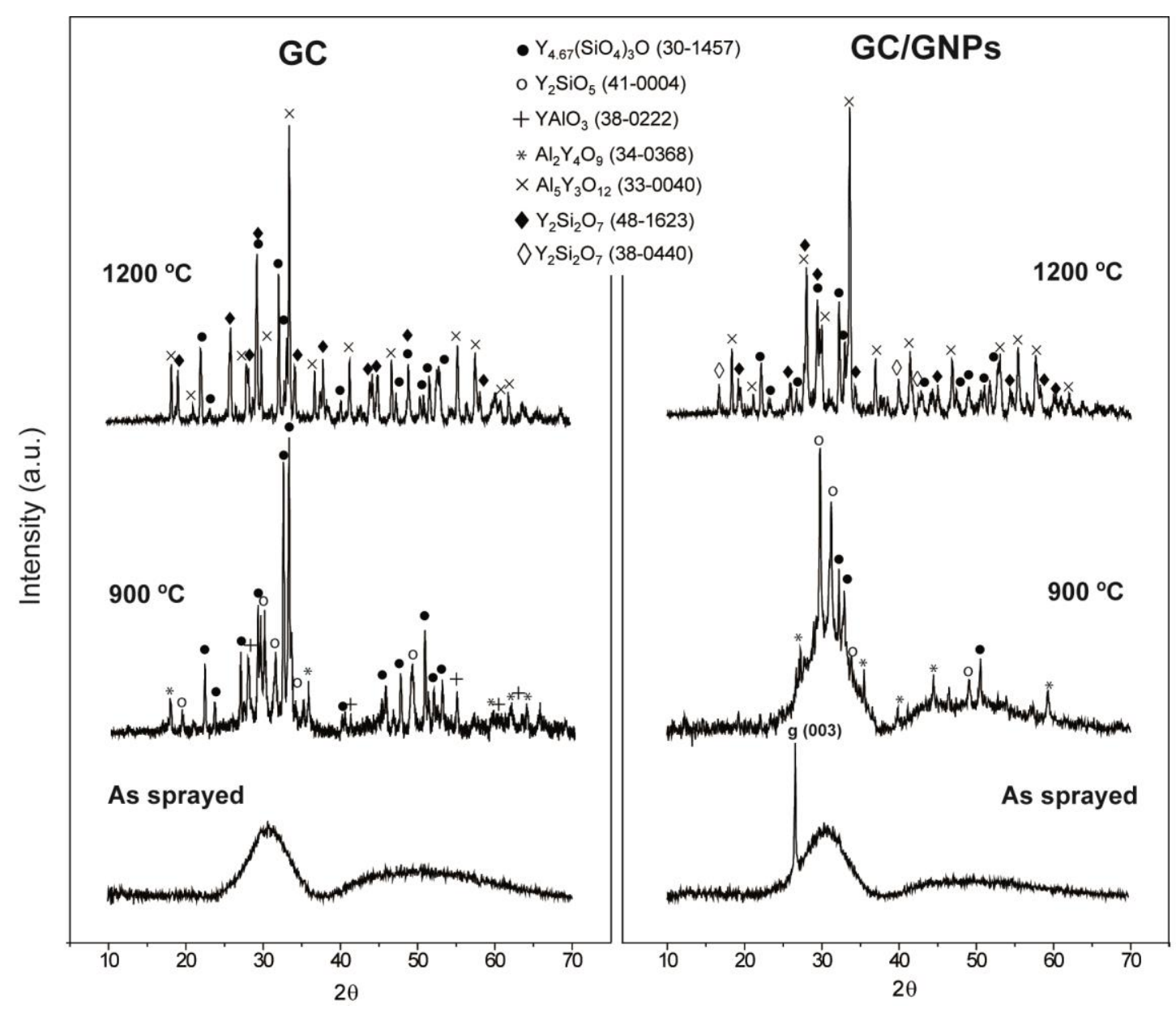

Figure 6. XRD patterns of the surface of the GC and GC/GNPs coatings (as-sprayed and ablated at 900 and $1200 \stackrel{\circ}{\circ}$ ), showing evolution of crystalline phases with the ablation temperature. 

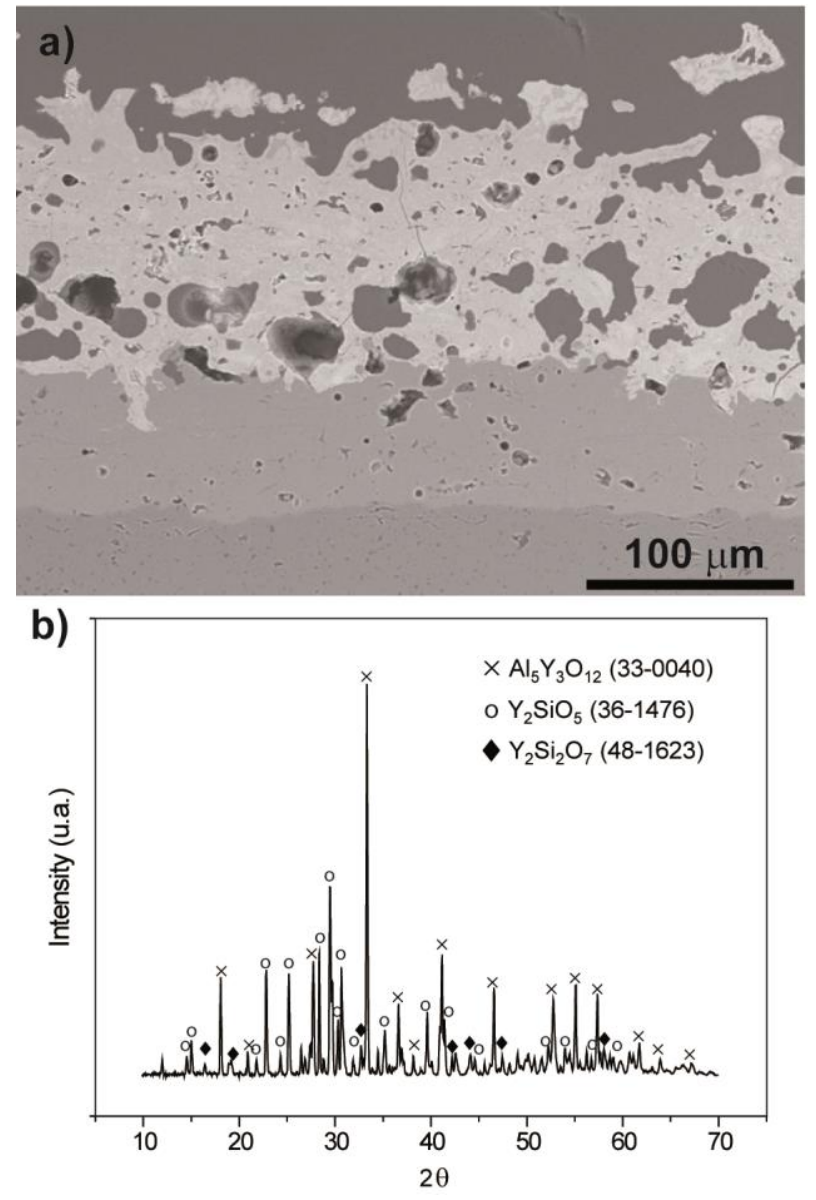

Figure 7. SEM micrograph of the GC/GNPs coating cross-section (a) and XRD pattern of

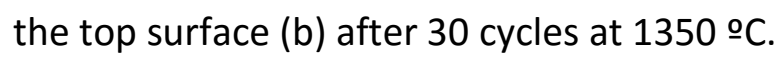

